\title{
Robótica na agricultura
}

\author{
Robotics in agriculture \\ Robotique dans l'agriculture \\ Robótica en la agricultura \\ Neusa Maria Hackenhaar* \\ (neusamaria@uft.edu.br) \\ Celso Hackenhaar* \\ (celso@uft.edu.br) \\ Yolanda Vieira de Abreu* \\ (yolanda@uft.edu.br)
}

Recebido em 24/01/2014; revisado e aprovado em 15/07/2014; aceito em 22/08/2014

DOI: http:/ /dx.doi.org/10.1590/1518-70122015110

\begin{abstract}
Resumo: Este estudo tem como meta mostrar a evolução dos robôs na agricultura nas últimas décadas, suas vantagens, desvantagens e seu estado da arte. Utilizou-se o processo metodológico exploratório, descritivo e bibliográfico. Observou-se que a utilização dos robôs na agricultura ainda enfrenta várias dificuldades, mas podese dizer que já é uma realidade consolidada e deve expandir-se continuadamente.

Palavras-chave: Robôs. Agricultura. Produção.

Abstract: This study aims to show the evolution of robots in agriculture in recent decades, its advantages, disadvantages, and its state of the art. We used the methodological process bibliographic descriptive and exploratory. It was noted that the deployment of robots in agriculture still faces various difficulties, but it can be said that is already a reality consolidated and expand continuously.

Key words: Robots. Agriculture. Production.

Résumé: Cette étude vise à montrer l'évolution des robots dans l'agriculture au cours des dernières décennies, ses avantages et inconvénients et son état de l'art. Nous avons utilisé le processus méthodologique bibliographique descriptives et exploratoires. Il a été noté que le déploiement des robots dans l'agriculture est toujours confronté à des difficultés diverses, mais on peut dire c'est déjà une réalité consolidée et d'élargir continuellement.

Mots-clés: Les robots. Agriculture. Production.

Resumen: Este estudio pretende mostrar la evolución de los robots en la agricultura en las últimas décadas, sus ventajas y desventajas y su estado del arte. Utilizamos el proceso metodológico bibliográfico descriptivo y exploratorio. Se observó que el despliegue de robots en agricultura todavía enfrenta varias dificultades, pero se puede decir que ya es una realidad consolidada y ampliar continuamente

Palabras clave: Robots. Agricultura. La producción.
\end{abstract}

\section{Introdução}

O crescente aumento demográfico implica um aumento da produção energia e alimentos; assim a eficiência agrícola deve ser triplicada nos próximos anos para sustentar o aumento da demanda por alimentos.

Uma das técnicas para intensificar a produção de alimentos é a robótica. Nos últimos anos, diversos avanços foram feitos no setor. A velocidade de operação dos robôs ultrapassou a de humanos e eles estão alcançando outras habilidades, podendo trabalhar continuamente e de forma consistente com o mínimo de manutenção (TANKE et al., 2011).

A robotização das atividades agrícolas deve considerar todos os agentes envolvidos na produção possibilitando a intensificação com o menor impacto possível. A exploração da agricultura de forma sustentável depende da conciliação conjunta entre variáveis como, por exemplo: 1) econômica, que se traduz através do lucro, aponta que, se a agricultura não gerar lucro e renda ao agricultor, ela desaparece; 2) social, porque, se o homem neste meio não obtiver dividendo, não há razão de ter da própria agricultura; 3) ambiental, que é a própria sobrevivência da natureza, para que possam existir agricultura e ambiente sadio no futuro. Portanto o tripé econômico, social e ambiental é o grande desafio atual da sustentabilidade e da agricultura. Aumentar a produtividade com sustentabilidade requer a utilização e o domínio de técnicas, metodo-

* Universidade Federal do Tocantins (UFT), Palmas, TO, Brasil. 
logias e instrumentos que, em boa parte das vezes, não estão adaptadas à real necessidade. Nesse aspecto, a agricultura deve ser direcionada para o desenvolvimento de métodos, processos, sistemas, sensores e equipamentos com vistas à integração dos sistemas de produção e que sejam sustentáveis (CRESTANA; FRAGALLE, 2012).

Este artigo tem como meta abordar os novos rumos da agricultura, apresentando os aspectos fundamentais da robótica, criação de máquinas inteligentes em ambientes de produção agrícola, exemplos de usos de robôs agrícolas, bem como indicar os principais desafios encontrados para a implantação de sistemas robóticos no ambiente agrícola, relacionar os problemas sociais e as expectativas geradas pela robotização.

\section{Material e método}

Este estudo foi realizado por meio do processo metodológico exploratório, descritivo e bibliográfico. Esses métodos foram adequados porque o objetivo foi descrever e apontar o estado da arte da robotização na agricultura. Por meio da pesquisa bibliográfica, pode-se explicar, descrever e analisar sua evolução, os tipos que estão disponíveis no mercado e outros que estão em desenvolvimento e o contexto tecnológico e social de sua implantação no campo.

A necessidade do aumento da produtividade, da qualidade e da eficiência na produção dos alimentos é de extrema importância. Aumentar a produtividade com sustentabilidade requer a utilização e o domínio de técnicas, metodologias e instrumentos que, algumas vezes, ainda não estão completamente desenvolvidos ou adaptados à realidade. Na prática de uma agricultura sustentável, é imprescindível a união do conceito econômico de aumento de produtividade com o de harmonia ambiental e social. O econômico se traduz por meio do lucro, por isso, se a agricultura não gerar lucro e renda ao agricultor, ela desaparece. A harmonia social significa que o homem poder viver do trabalho agrícola e manter sua família com dignidade de forma se sentirem compensados pelo esforço ou investimento realizado. A harmonia ambiental é a convivência do homem e natureza de forma que o primeiro respeite a segunda em seus limites, direitos à vida e a todo ecossistema envolvido de forma a manter a sua própria sobrevivência e o da natureza, também, para que possam existir agricultura e um meio ambiente sadio e equilibrado que possa garantir sua continuidade. O tripé econômico, social e ambiental é o grande desafio atual da sustentabilidade e da agricultura. Nesse cenário, Crestana e Fragalle (2012), em levantamento de estudo realizado na Embrapa, apontam para áreas consideradas "portadoras de futuro", sendo:

- Sensores e metodologias para monitoramento que avaliem características físicas, químicas e biológicas referentes à qualidade do ambiente, de processos agroind ustriais e das cadeias do negócio agrícola;

- Agricultura de Precisão, com ênfase no desenvolvimento de instrumentos, sensores de leitura imediata, técnicas de sensoriamento remoto, imagens aéreas, previsão de safra, técnica de reconhecimento de zonas de manejo;

- Técnicas não invasivas aplicadas à agricultura e monitoramento ambiental, como por exemplo, as técnicas espectroscópicas e de imagens, associadas aos métodos estatísticos e computacionais de análise;

- Aplicação de nanotecnologia e produção de nanomateriais de interesse agrícola, máquinas, equipamentos e instrumentos que melhorem os processos na cadeia agrícola e o potencial de trabalho humano;

- Demanda de sensores nas embalagens para indicação da qualidade e no auxílio à rastreabilidade;

- Demanda internacional pelo desenvolvimento de etanol celulósico, compreendendo equipamentos, processos, metodologias de caracterização e desenvolvimento de insumos;

- Demanda por produtos agrícolas com propriedades funcionais, como aqueles recobertos com filme ou película impregnados com indicadores de contaminação microbiológica;

- Demanda por técnicas de avaliação da qualidade do solo - incluindo macro e micronutrientes e contaminantes mais rápidas e eficientes;Demanda 
por técnicas práticas para avaliação de características físicas do solo, como granulometria, curva de retenção de água, resistência à penetração e permeabilidade;

- Desenvolvimento de sistemas portáteis de classificação de frutas e hortaliças para pequenos e médios empreendedores;

- Elevada demanda por novas técnicas para avaliação de aspectos relacionados às mudanças climáticas globais e de ilhas de calor, emissão de gases de efeito estufa, poluentes e ciclo da água.

Neste aspecto, a tendência da agricultura deve ser direcionada para o desenvolvimento de métodos, processos, sistemas, sensores e equipamentos com vistas à integração dos sistemas de produção e que sejam sustentáveis.

\section{Resultados e discussão}

A sucessão do desenvolvimento tecnológico trouxe maior produtividade e eficiência econômica à agricultura, horticultura e silvicultura. Historicamente o fator gerador foi a mecanização de campos que gradativamente foram se tornando maiores. Atualmente a tendência é a substituição das máquinas grandes e pesadas por tecnologias baseadas nas informações que podem propiciar operações autônomas viáveis e confiáveis em campo (EARL et. al, 2000).

Robótica é o termo utilizado para indicar a disciplina associada ao uso e programação de robôs. A Engenharia Robótica refere-se à construção de robôs e dispositivos robóticos. Sendo assim robô, conforme denominado na norma ISO (International Organization for Standardization) 10218 (1992) "é uma máquina manipuladora com vários graus de liberdade controlada automaticamente, reprogramável, multifuncional, que pode ter base fixa ou móvel para utilização e aplicações de automação industrial".

Os robôs podem ser classificados quanto a sua aplicação de construção, em dois tipos distintos: robôs industriais e robôs não industriais. As aplicações, limitações, modelos e formas fazem com que se sejam divididos em dois tipos básicos (SILVEIRA, 2012).
- Robô Fixo: conhecido como braço robótico. É composto por uma base fixa e um conjunto de elos e juntas que lhe conferem movimentos em várias direções. Por ser muito empregado em aplicações industriais, tornou-se o tipo mais comum de robô.

- Robô Móvel: normalmente chamado de veículo robótico, pode se apresentar de diversas formas e modelos distintos. Geralmente possuem certo grau de assistência inteligente para a locomoção ou para o controle do sistema, dos quais citamos: AGV (Automatically Guided Vehicle) veículo guiado automaticamente, geralmente terrestre sobre rodas, pernas ou lagartas; $U A V$ (Unmanned Aerial Vehicles) veículos aéreos não tripulados, são geralmente aeronaves e helicópteros sem pilotos; AUV (Autonomous Underwater Vehicles) veículos submarinos autônomos, são inteligentes e sem tripulação e $R O V$ (Remotely Operated Vehicle) veículos operados remotamente, são em geral submarinos robôs com transmissão de controle por cabo umbilical.

Os robôs industriais possuem um espaço limitado de movimentação dos manipuladores, denominado de espaço ou volume de trabalho, onde o sistema robótico pode se posicionar e usar a ferramenta (end-effector). A robótica foi desenvolvida com diferentes objetivos, muitas vezes, todos estes, ao mesmo tempo. Estes incluem a criação de controladores úteis para trabalhos de robôs do mundo real, exploração de detalhes, fenômenos psicológicos, dentre outros (SILVEIRA, 2012).

O uso de robôs como veículos agrícolas autônomos, possui um interessante potencial como uma valiosa ferramenta tecnológica para a agricultura de precisão, trazendo a vantagem de poder fazer uso das diversas teorias em controle robótico, já fundamentadas e consolidadas para aplicações em diversas outras áreas (TANGERINO et al., 2011).

A tendência recente de desenvolvimento de robôs móveis e veículos autônomos para realização de tarefas específicas é norteada principalmente por melhorar a eficiência e originar ganhos de operação (reduz compactação do solo, ausência de operador) quando comparados com a utilização de grandes 
máquinas (BLACKMORE; GRIEPENTRONG, 2006).

A robótica na agricultura não é um conceito novo, em ambientes controlados (estufas) tem uma história de mais de 20 anos. Estudos vêm sendo realizados para desenvolver colheitadeiras para o tomate cereja, pepino, cogumelos, e outras frutas. Na horticultura, robôs foram utilizados para a colheita de citrinos e maçãs. Em criação de gado leiteiro, a ordenha realizada por robôs é muito comum na Holanda (NOGUCHI, 2010). No entanto o maior desenvolvimento de sistemas de produção agrícola automatizados encontrase, sem dúvida, entre os japoneses. Desse desenvolvimento, podemos citar a "Fábrica planta", onde os vegetais são cultivados em sistema hidropônico sob iluminação artificial. Computadores e robôs controlam o processo de plantio de mudas, adubação, sanidade, o corte da raiz, embalagem e pesagem, tendo como resultado, produtos perfeitos, ou seja, sem defeitos, doenças ou danos causados por insetos. O nível de automatização nas fábricas de planta é tão elevado que, ao longo do tempo, podem tornar-se instalações de produção completamente autônomas (NOGUCHI, 2010).

O uso da robótica no campo é relativamente novo, embora Hollywood, em 1984, tenha produzido um filme chamado "Fuga" no qual os robôs agrícolas são projetados como olheiros para arrancar insetos das folhas do milho. No entanto o primeiro robô para aplicações agrícolas de campo foi desenvolvido, em 1998, por Astrand e Baerveldt para o controle de ervas daninhas (ASTRAND; BAERVELDT, 2002). Em 2004, Bak e Jakobsen desenvolveram um pequeno robô capaz de viajar entre as linhas das culturas para registrar a localização de plantas daninhas usando uma câmera e um Sistema de Posicionamento Global (GPS) receptor. Também em 2004, Hofstee, Grift e Tian desenvolveram um algoritmo de visão de máquina com base para culturas de campo com orientação autônoma (GRIFT, 2007).

Os agricultores têm necessidade de colher informações sobre a cultura e o solo, seu estado antes e durante a estação de crescimento, como por exemplo: robôs batedores, que podem viajar para um local pré-determinado, retirar uma amostra do solo para identificar os níveis de umidade usando um penetrômetro de cone, tipo de sonda que é inserida no solo para medir a compactação, e utilizar uma sonda elétrica para medir o $\mathrm{pH}$. Durante o estágio de desenvolvimento, a necessidade recai em medir o nitrogênio e stress hídrico em plantas, utilizando os sensores ópticos, bem como infestações de insetos e plantas daninhas usando câmeras (GRIFT, 2007). Este mesmo autor afirma que a nova geração de robôs agrícolas apresenta resultados satisfatórios. Embora muito menor do que máquinas agrícolas convencionais, eles podem agir de forma cooperativa e realizar tarefas como a pulverização com agrotóxicos que apresentam riscos ao ser humano. Os lasers são usados para várias tarefas, desde a colheita a capina (GRIFT, 2007).

A nova geração de robôs leves, com pneus de baixa pressão, revolverá o volume mínimo de solo para permitir a acomodação das sementes. Estas por sua vez serão precisamente semeadas de acordo com os níveis de umidade do solo. Seus movimentos serão controlados por software específicos - SAFAR (Arquitetura de Software para Robôs Agrícolas), e as rotas serão planejadas por meio do Google Earth. Os robôs ainda serão capazes de colheita seletiva, permitindo aos agricultores obter uma maior qualidade de corte, enquanto as plantas que ainda necessitam de tempo para crescer, são deixados no campo (GRIFT, 2007).

Embora os robôs ainda sejam pequenos para efetuar tarefas que requerem alta capacidade de armazenamento, como carregar fertilizantes e remover os grãos colhidos, eles podem ser usados em situações em que há necessidade de energia relativamente baixa. Um bom exemplo disso é a capina, na qual as ervas daninhas podem ser tratadas com uma pequena quantidade de produto químico, altamente concentrado ou controle de plantas daninhas de forma mecânica (NOGUCHI, 2010).

Um fator limitante de robôs de campo é o seu consumo de energia, que interfere no seu raio de ação. Embora os robôs possam ser alimentados por combustíveis fósseis, o adequado é a utilização de fontes disponíveis no local, como luz solar, energias renováveis ou biocombustíveis para diminuir o impacto ambiental. Se os robôs são usados para co- 
lheita, eles podem até consumir algumas das culturas para sua própria operação. Pode-se afirmar que este é semelhante ao uso homólogo biológico tais como uma colheita de feno com uso de cavalos (NOGUCHI, 2010).

Os robôs agrícolas variam de grandes polivalentes quadros mecânicos, para pequenos veículos autônomos construídos para aplicações específicas. A concepção do robô é geralmente determinada pelo ambiente em que opera. Ambientes ao ar livre, geralmente permitem a utilização de robôs de grande porte, como tratores autônomos. No entanto os robôs exteriores requerem sofisticados sistemas de navegação para explorar um ambiente desestruturado (CHEN, 2012). No entanto os robôs usados em interiores de lojas, galpões, fábricas de plantas e outros podem tirar proveito da infraestrutura dentro de seu ambiente, como por exemplo, as condições controladas de iluminação podem aumentar a confiabilidade do sistema de visão que permite o desenvolvimento de robôs mais sofisticados de cultivo (CHEN, 2012).

Os robôs para áreas externas ou não protegidas, em grande parte, dizem respeito à navegação, planejamento de trajetória e evitar obstáculos. Durante a última década, essa área de pesquisa fez a transição de controlar um trator autônomo único, para a coordenação de vários tratores autônomos. Por exemplo, um sistema recente pode colher 100 campos de musgo de turfa durante uma estação utilizando três tratores autônomos. Cada trator foi capaz de se direcionar a um campo, colher o musgo de turfa, direcionar-se a um local designado e descarregá-lo de forma autônoma (CHEN, 2012). Este mesmo autor ainda afirma que outros robôs agrícolas, para atuação ao ar livre, se concentram no implemento agrícola em vez do trator. Por exemplo, pulverizadores rebocados robóticos podem direcionar bicos para as ervas daninhas por meio de um sistema de visão artificial. Tais sistemas têm sido experimentrados nas culturas de tomate e algodão. O pulverizador seletivo desenvolvido por Lamm et al. (2002), foi capaz de identificar corretamente e pulverizar $88 \%$ das plantas daninhas em uma lavoura de algodão.

Os projetos em andamento incluem automação completa para culturas especiais, que se concentra em aumentar a eficiência da produção e diminuindo os custos do trabalho na indústria, com uma atenção especial a frutas e produção de mudas. Isso levou ao desenvolvimento de veículos de utilidade para a automação robótica em pomares e na criação de sistemas que detectam stress das plantas, doenças, insetos, o diâmetro da árvore medida, contagem e tamanho de frutos antes da colheita (CHEN, 2012).

Outro projeto voltado ao gerenciamento de irrigação e de nutrientes através de sensoriamento distribuído, centra-se na economia de água, aumentando a eficiência e redução dos impactos ambientais das práticas de produção agrícola, usando os dados da rede de sensores com modelos de fisiologia de plantas para a irrigação automatizada e gestão de nutrientes em culturas ornamentais (SANCHEZ, 2011).

A hidroponia é uma boa plataforma para automação robótica porque exige um trabalho periódico, uma abordagem sistemática, movimento repetitivo e um ambiente estruturado. Assim, combinando hidroponia e melhorias robóticas obtém-se eficiência de crescimento de plantas, aumento da produtividade e diminuição das perdas (TANKE et al., 2011).

Quanto a robôs e veículos autônomos construídos especificamente para trabalhos em estufas, Sanchez (2011) aponta alguns estudos: Sandini et al. (1990) e Dario et al. (1994) desenvolveram o Agrobot projeto, que foi uma plataforma móvel com estereoscópica visão e um braço manipulador com uma pinça/mão. Mandow et al. (1996) descreveram um veículo autônomo (Aurora) para a pulverização de culturas. Subramanian et al. (2005) e Singh et al. (2005) descreveram um minirrobô para realizar atividades de pulverização, cuja navegação é controlada por algoritmos baseados em lógica fuzzy. Belforte et al. (2006) descreveram uma plataforma autônoma desenhada para avaliar a saúde da planta. Kitamura e Oka (2005) desenvolveram um robô para colheita de pimentas doces em estufa. Outro robô para colheita de pepinos foi desenvolvido pela Van Henten et al. (2002).

Derek Morikawa, coordenador de um projeto de automatização de colheita de frutas com dois protótipos robôs: o primeiro localiza todas as frutas a serem colhidas e o segundo, coleta cada uma delas. O primeiro robô é dotado de um sistema de visão artificial que 
rastreia toda a plantação, construindo um mapa 3-D da localização e do tamanho de cada fruta. Na sequência, ele calcula a melhor ordem para que elas possam ser colhidas. A informação é enviada para o segundo robô, dotado de oito braços. Trabalhando de forma coordenada, os braços nunca se cruzam, otimizando a tarefa de pegar todas as frutas previstas (INOVAÇÃO TECNOLÓGICA, 2007).

A Universidade de Osnabrück, Alemanha em parceria com a Bosch, desenvolveu um robô, denominado BoniRob, com quatro rodas articuladas individualmente, movendose sem motorista, sem um controle remoto, medindo diferentes características de cada planta, como por exemplo: se as plantas estão bem nutridas, se estão sob estresse hídrico ou indicativo de doenças. Pesando cerca de $500 \mathrm{~kg}$, está equipado com uma série de sensores, eletrônica e software. O módulo de navegação avalia os dados de medição de um scanner a laser 3D, que servem para acionamento dos motores do cubo de roda. As primeiras aplicações do BoniRob foi o melhoramento de plantas e as pesquisas de campo (RUCKELSHAUSEN, 2010).

Um estudo que vem sendo realizado no Japão num sistema de veículos robóticos usando RTK-GPS (sistema em tempo real e posicionamento cinemático global) e GIS (sistema de informação geográfica), com vistas a automatizar totalmente a cadeia produtiva, isto é. deste de a produção agrícola até a comercialização e a entrega do produto ao usuário final (NOGUCHI, 2010).

O robô para transplante de arroz, desenvolvido em NARO (Japão) foi modificado para executar uma operação completamente automatizada, com a adição de servo-motores de corrente contínua, para o funcionamento do regulador de pressão, da engrenagem de transmissão (CVT) com a embreagem do implemento, das válvulas hidráulicas de controle, da direção e válvulas hidráulicas electromagnéticas para operar os travões esquerdo e direito, embreagens e elevador. Também emprega uma RTK-GPS e sensores de navegação. O robô de transplante pode viajar dentro de uma margem de erro de \pm $10 \mathrm{~cm}$ a partir do caminho pré-determinado. Embora plântulas de arroz devam ser fornecidas manualmente, o uso da esteira ao longo das plântulas de arroz (hidropônico) permite ao robô transplantar até $3.000 \mathrm{~m}^{2}$ de área a um ritmo de 0,2 minutos/ha sem reabastecer plântulas. O robô colheitadeira possui funções de controle de velocidade, controle de altura do cabeçalho, sistema de nivelamento automático similar a uma colheiradeira convencional (NOGUCHI, 2010).

O sistema de gestão do robô desenvolvido com base em um SIG integrado agrícola (YAMAGATA, 2011) pode lidar com vários tipos de dados, tais como: informações de campo, tipo de cultura, tipo de solo, produtividade, qualidade, informações do agricultor, custo, química e de fertilizantes. Este sistema tem uma função de comunicar com os veículos do robô sobre o estado dos trabalhos como a eficiência do trabalho, nível de combustível, fertilizante e substâncias químicas contidas em cada tanque. O sistema de gestão do robô também pode obter dados de informação de safra dos veículos robô, usando um sensor de visão inteligente. Outra função do sistema de gestão do robô é a monitorização em tempo real dos veículos robô enquanto na condição de funcionamento. No caso da colheitadeira, cada campo é representado por uma cor, de acordo com o seu estado de colheita: não colhida, em colheita e colhida. Usando esse sistema de gestão, pode ser vizualizada a localização atual e o estado dos veículos (NOGUCHI, 2010).

Profissionais do Núcleo de Ensino e Pesquisa em Automação e Simulação, Engenharia Mecânica, EESC-USP e da Embrapa Instrumentação estão desenvolvendo uma plataforma robótica modular e multifuncional para aquisição de dados em Agricultura de Precisão. A plataforma é capaz de se locomover em ambientes típicos da área agrícola, com a finalidade de aquisição de dados e pesquisa de novas tecnologias para o sensoriamento remoto para a área agrícola. Suas principais características são: robustez, mobilidade, elevada capacidade operacional e autonomia condizente com as necessidades agrícolas.

De acordo com Tangerino et al. (2011), a plataforma robótica base apresentará característica multifuncional no sentido de permitir o acoplamento de módulos para aquisição de dados em campo, visando ao estudo da variabilidade espacial por meio de sensores e equipamentos considerados portáteis. 
Em 1999, a Empresa Brasileira de Pesquisa Agropecuária (EMBRAPA) desenvolveu um sistema integrado para controle da produção agrícola que considera a variabilidade dos parâmetros do solo. As entradas consistem de dados que envolvem análises laboratoriais, dados coletados automaticamente por sensores estáticos (instalados no campo) e dinâmicos, como também, dados obtidos por sensoriamento remoto. Os dados de posicionamento são fornecidos por GPS. O processamento integra sistemas GIS com técnicas de geoestatística, programas de modelamento, entre outros, para estabelecer e gerar mapas de controle.

Outra tecnologia desenvolvida pela Embrapa (JORGE; TRINDADE JUNIOR, 2002) é um aeromodelo construído a partir de kits convencionais com câmera digital adaptada à aeronave, disparada através de equipamento de rádio controle. $\mathrm{O}$ aeromodelo facilita levantamentos topográficos, obtenção de mapas detalhados das propriedades e avalia o estado das lavouras que sobrevoa, sendo possível identificar os pontos dos terrenos que estão sujeitos à erosão, localizar pragas na lavoura e detectar deficiências nutricionais.

Uma tecnologia elaborada para monitoramento remoto de variáveis ambientais é o Sistema de Aquisição de Dados em Ambiente Agropecuário, que possibilita a leitura de até 250 sensores, sendo adequado também para controle automático de irrigação. O sistema permite monitorar à distância, sensores na área agrícola, possibilitando a leitura de inúmeras variáveis de interesse para automatização de processos em uma fazenda, entre os quais a irrigação controlada por sensores de umidade do solo (tensiômetros) e por sensores ambientais climatológicos. Estes, constituídos de sensores "inteligentes" com monitoramento automático de dados ambientais e, também, sobre o solo, cuja transmissão é realizada via rádio-modem (INAMASU et al., 1996).

A Sonda Termoelástica, equipamento destinado a identificar o estado de hidratação da planta, foi construída com tecnologia brasileira e seu funcionamento recorre a uma técnica simples e inédita no mundo. Esta é capaz de medir a pressão interna de células vegetais e a sucção de raízes, e dessa maneira identifica o estado de hidratação da planta. A Sonda é composta basicamente de um sensor, uma fonte de tensão/corrente e um microscópio. Seu principal componente, um sensor de vidro, é um capilar com volume interno da ordem de microlitros que deve puncionar a célula (nas medidas de pressão), ou encostarse ao tecido (nas medidas de sucção). O sensor contém um óleo mineral devidamente tratado e água, que devem ser mantidos à temperatura constante durante as medidas (BERTUCCI NETO et al., 2006).

A pulverização agrícola robotizada desempenha um papel de extrema importância tanto no setor econômico como social no mundo. O sistema propicia pulverização com precisão, realizando em tempo real a coleta de informações de posição, incidência de doenças e pragas, transmitindo-as a um atomizador ou pulverizador que regula a necessidade de maior ou menor quantidade de defensivos. Além da diminuição do desperdício, melhora as condições de trabalho do agricultor, uma vez que não terá contato com produtos altamente tóxicos que poderão levá-lo a problemas de saúde e, no pior dos casos, a óbito (BERTUCCI NETO et al., 2006).

Um estudo realizado na China resultou no desenvolvimento de um robô para pulverização e coleta de informações em tempo real com o erro variável inferior a $10 \%$. Outro sistema robótico desenvolvido foi o de controle de plantas invasoras, este sistema é composto por uma câmara digital, um computador, depósito químico e um sistema de locomoção, cuja eficiência permite a economia de $90 \%$ de herbicida aplicado (LIBIN et al., 2008).

\subsection{Entraves e perspectivas da robótica agrícola}

Os sistemas robóticos não foram totalmente implantados na agricultura, por uma série de razões das quais se pode citar: fragilidade das máquinas, tecnologia mecânica dispendiosa, trabalho sob limite da capacidade da máquina, bem como a eficiência do trabalho ainda a ser melhorado e adaptado a diversas situação. Além disso, em um ambiente ao ar livre, é difícil espalhar os custos de capital em diversas operações, porque a maioria dos robôs são desenvolvidos para uma única aplicação, e a necessidade é tipicamente disponível em somente uma estação (INAMASU, 2011). 
A viabilidade econômica do sistema é largamente determinada pela função do robô. Alguns robôs agrícolas são projetados para um processo caro, como a colheita, que pode representar até $40 \%$ do custo total de produção hortícola nos Estados Unidos. Um robô de inspeção de uma estufa, em vez de agregar, protege contra perdas por permitir que um problema seja detectado mais cedo. A maior parte dos custos de produção agrícolas são calculados por metro quadrado; assim aumentar a eficácia por área sem aumentar o tamanho da área cultivada pode ser uma alternativa econômica (OLIVEIRA, 2009).

Segundo Inamasu (2011), o escopo das pesquisas foca no desenvolvimento individual do projeto de cada robô, e não nas necessidades da agricultura em relação aos robôs. Essa condição faz com que os projetos de robôs não atinjam o nível máximo de qualidade. Assim, uma das técnicas que pode ser aplicada é a análise sob múltiplas perspectivas, possibilitando uma visão sistêmica dos pontos fortes e fracos do projeto. Nesse contexto, são consideradas oito perspectivas que devem ser abordadas no processo de desenvolvimento: segurança, energia, economia, meio ambiente, gerenciamento, mecanização, tecnologia e sociedade. No que tange ao sistema móvel em si, estes devem superar problemas relacionados à limitação de recursos computacionais e alimentação, devido a restrições quanto à mobilidade do sistema.

Recorrente a esse aspecto, o desafio é projetar esses complexos sistemas com configuração móvel com baixo consumo de energia, mantendo o alto poder computacional requerido. Um bom projeto depende de um equilíbrio entre os fatores como custo, tamanho, alimentação, desempenho e complexidade, com as funções requeridas.

Atualmente o custo para a robotização agrícola ainda é muito elevado, mas à medida que a demanda de uma tecnologia aumenta, seu custo total diminui, seja pela diluição do investimento gasto no desenvolvimento da tecnologia, seja pelo decréscimo do custo de produção em larga escala.

Outro ponto que se deve levar em consideração é a resistência intrínseca existente nesse setor por parte dos agricultores, referente às mudanças na forma de manejo pratica- das, havendo a necessidade do entendimento de que a automação não é uma solução imediatista à determinada carência ou problema, mas parte de um processo gerencial.

\subsection{Desenvolvimento da tecnologia robótica}

De acordo Oliveira (2009), até o presente estágio de desenvolvimento da tecnologia, a adoção da robótica vem sendo estimulada principalmente pela avaliação do retorno econômico, essencialmente promovido pela eficiência na aplicação diferenciada de insumos. Entretanto a tecnologia deve ser entendida como um sistema de produção agrícola que integra a informação dentro de uma visão holística da produção. Dessa forma, robótica visa ao incremento simultâneo da eficiência no manejo da produção, do aprendizado na gestão do conhecimento agronômico e, em longo prazo, ao lucro das propriedades rurais mediante uma gradativa minimização dos impactos indesejáveis no meio ambiente e na vida selvagem.

Ensaios científicos em propriedades produtivas estimam uma rentabilidade no uso da tecnologia da ordem de trinta dólares por hectare (US\$30.00/ ha), quando considerada a redução no desperdício na aplicação de fertilizantes. Outros estudos específicos indicam ganhos líquidos em dólares por acres de US\$48.25/A no uso de nitrogênio para o cultivo de beterraba; US\$5.00/A no uso de calcário para fins de correção da fertilidade do solo; e US\$7.00/A no uso de inseticidas para o combate de ervas daninhas (INAMASU, 2011).

Entretanto esse tipo de benefício econômico é difícil de ser caracterizado, uma vez que a conversão das informações monitoradas traduzidas em métricas financeiras nem sempre é fácil de ser estabelecida. Como comprovação disso, uma grande variação na rentabilidade anual das fazendas pode ser observada nos relatos de agricultores comerciais de grãos que investiram na tecnologia de agricultura de precisão nos últimos dez anos. Essas variações oscilam entre US $\$ 11$ e US $\$ 48$ por hectare nos Estados Unidos, e de US $\$ 9$ a US\$33 por hectare em regiões da Austrália (OLIVEIRA, 2009).

No Brasil, vários fatores sugerem uma adoção relativamente lenta e heterogênea 
(LOWENBERG; GRIFFIN, 2006), como na verdade vem ocorrendo no resto do mundo. Entre os fatores preponderantes da limitada adoção da tecnologia no país destaca-se: mão de obra barata, número limitado de computadores em fazendas; altas taxas de importação para equipamentos de última geração; suporte técnico insuficiente e despreparado; baixo valor de mercado dos produtos agrícolas; baixa escala de produção na maioria das fazendas; e o preço relativamente baixo das terras.

De modo simples, pode-se afirmar que os benefícios potenciais da robótica são o aumento na quantidade e na qualidade dos produtos e a melhoria na gestão dos recursos naturais, mediante o uso eficiente de insumos. Apesar de propor uma solução altamente tecnificada e ainda pouco acessível à maioria dos sistemas produtivos da agricultura familiar, a robótica e a tecnologia da agricultura de precisão basicamente potencializam o aumento na produção e no valor energético dos grãos, mediante um manejo específico e localizado na aplicação de insumos. Esse manejo mais eficiente propicia um rendimento da cultura que tende a atingir os níveis máximos da capacidade produtiva dos talhões, muitas vezes incrementando a média da produtividade de grãos de duas toneladas e meia por hectare (2,5 t/ha) para até oito (8t/ha), no caso do trigo (INAMASU, 2010).

Segundo estimativas da UNEP (United Nations Environmental Programme) em 2009, até $25 \%$ da produção mundial de alimentos podem estar ameaçadas no decorrer deste século, como resultado da escassez de água, pragas mais agressivas e resistentes aos pesticidas, e avançada degradação dos solos. Nesse sentido, uma contribuição social significativa pode ser atribuída como consequência das tecnologias, se considerado o desafio de aumentar a produção de alimentos em resposta às demandas de uma crescente população, de uma redução da degradação ambiental e de uma redução dos acidentes nas atividades mais perigosas (OLIVEIRA, 2009).

Por outro lado, a questão da automação e de sua repercussão sobre o nível do emprego passou recentemente a ser discutida com maior insistência no Brasil. O processo de introdução e difusão desse conjunto de tecnologias de ponta deve ser acompanhado de transformações estruturais de natureza socioeconômica, de modo a engendrar as condições de rentabilização das novas técnicas.

Ao contrário de indústrias como a aeroespacial, a agricultura é uma indústria de margem pequena de lucro, por isso é vital que os novos robôs sejam robustos e acessíveis. Agricultura daqui a 20 anos será uma mistura do tradicional com o novo, mas os novos robôs deverão ser inteligentes o suficiente para trabalhar com o ambiente natural para manter a competitividade econômica e sustentável, e a produção de alimentos de alta qualidade (EUROBOTICS, 2012).

A multidisciplinaridade e os avanços tecnológicos que passam a envolver as novas práticas agrícolas abrem a oportunidade para inserção de sistemas autônomos no campo. Esse, por sua vez, deve ser interpretado como uma ferramenta de auxilio que irá compor e incrementar o sistema de manejo e não como uma solução isolada e imediatista (INAMASU, 2011).

\section{Considerações finais}

A discussão das novas tecnologias no processo produtivo rural é muito incipiente, assim como a discussão do que o impacto destas poderá causar no processo de trabalho rural. Sabe-se que o desenvolvimento tecnológico, sob o capitalismo, promoveu uma diminuição significativa do número de trabalhadores rurais no mundo. E o atual desenvolvimento tecnológico apresenta-se mais excludente para os trabalhadores.

As máquinas mudaram o jeito de viver do agricultor em muitos lugares. Hoje, a maioria dos fazendeiros e seus empregados devem saber operar maquinário sofisticado e fazer-lhes a manutenção. Seu trabalho tem se tornado cada vez mais solitário. Aquele espírito de camaradagem típico do semear, capinar e colher em grupos deixou de existir.

Em muitos países, surgiu um novo tipo de agricultor: um homem de negócios com formação acadêmica, especializado na produção em massa de poucos produtos agrícolas ou de apenas um. Ele investe muitos recursos em terras, instalações e maquinário. Mas está longe de ser independente. Grandes empresas de processamento de alimentos e redes de supermercado ditam o preço, a variedade, o 
tamanho e a cor dos produtos. Engenheiros agrônomos projetam para ele sistemas de produção, e empresas especializadas lhe fornecem os tipos certos de fertilizante, pesticida e semente híbrida, necessários para as condições de sua fazenda. $\mathrm{O}$ agricultor moderno progrediu bastante em comparação com seus antepassados, mas ainda enfrenta muitos desafios e a preocupação com os possíveis efeitos nocivos de certas técnicas de cultivo mais intensa.

A tecnologia pode desempregar, mas também, em outro projeto social, pode facilitar o trabalho e aumentar a produção. Assim, há necessidade de um controle hegemônico das tecnologias, para que se possa ter uma sociedade onde a terra, o trabalho, a técnica e os seus frutos possam ser socializados.

\section{Referências}

ASTRAND, B.; BAERVELD, J. An Agricultural Mobile Robot with Vision-Based Perception for Mechanical Weed Control. Autonomous Robots, Los Angeles, v. 13, n. 3, p. 21-35, 2002.

BELFORTE, G. et al. Robot Design and Testing for Greenhouse Applications. Biosystems Engineering, v. 95, n. 3, p. 309-321, 2006.

BERTUCCI NETO, Victor et al. Modelagem e automação de uma sonda termoelástica para medidas de parâmetros relativos a fisiologia vegetal. Boletim de Pesquisa e Desenvolvimento, Embrapa Instrumentação Agropecuária, São Carlos, SP, n. 14, nov. 2006. Disponível em: <http:/ / ainfo.cnptia.embrapa.br/digital/bitstream/ CNPDIA-2009-09/11849/1/BPD14_2006.pdf>. Acesso em: out. 2012.

BLACKMORE, S. M.; GRIEPENTRONG, H. W. Autonomous Vehicles and Robotics. Chapter 7, Section 7.3 Mechatronics and Applications, ASAE CIGR Handbook of Agricultural Engineering, v. 6, p. 204-215, 2006.

CHEN, H. Design of a controlled environment agricultural plant inspection robot. Thesis (Master of Science Industrial Engineering) - University of Iowa, 2012. Disponível em: <http://ir.uiowa.edu/etd/2838>. Acesso em: $1^{\circ}$ out. 2012.

CRESTANA, S.; FRAGALLE, E. P. A Trilha da quinta potencia: um primeiro ensaio sobre ciência e inovação, agricultura e instrumentação agropecuária brasileira. Revista Eixo, Brasília, v. 1, n. 1, p. 6-27, 2012.

CRUVINEL, Paulo Estevão; TORRE-NETO, André. Agricultura de precisão: fundamentos, aplicações e perspectivas para a cultura do arroz. Comunicado Técnico, Embrapa Instrumentação Agropecuária São Carlos, SP, n. 30, p. 1-6, jul. 1999. Disponível em: <http://www. infoteca.cnptia.embrapa.br/bitstream/doc/29572/1/ CT3099.pdf>. Acesso em: out. 2012.

DARIO, P. et al. The Agrobot Project for Greenhouse Automation. Acta Hort. (ISHS), v. 361, p. 85-92, 1994.
EARL, R.; THOMAS, G.; BLACKMORE, B. S. The potencial role of GIS in autonomous field operations. Computers and Eletronics in Agriculture, v. 25, p. 107-120, 2000.

EUROPEAN ROBOTICS COORDINATION EUROBOTICS. Challenge 2: Cognitive Systems, Interaction, Robotics. (FP7-ICT-244852; 01/2010-12/2012). Disponível em: <http://www.eurobotics-project.eu>. Acesso em: out. 2012.

GRIFT, T. E. Robotics in Crop Production. Illinois, U.S.A.: Urbana, 2007. Disponível em: <abe.illinois.edu/ faculty/t_grift/publications>. Acesso em: out. 2012.

INAMASU, R. Novas tecnologias a serviço da AP: produtos ISOBUS e telemetria. In: CONGRESSO BRASILEIRO DE AGRICULTURA DE PRECISÃO - ConBAP2010. Ribeirão Preto, SP, 2010.

- Agricultura de precisão para a sustentabilidade de sistemas produtivos do agronegócio brasileiro. Ribeirão Preto, SP: Embrapa Instrumentação Agropecuária, 2011.

INAMASU, Ricardo Y. et al. Sistema de informação em elementos de aquisição de dados para ambiente agropecuário. Pesquisa em Andamento, Embrapa Instrumentação Agropecuária, São Carlos, SP, n. 10, p. 1-8, dez. 1996. Disponível em: <http:/ / ainfo.cnptia.embrapa.br/ digital/bitstream/CNPDIA/9807/1/PA10_96.pdf>. Acesso em: out. 2012.

ISO 10218 - Manipulating Industrial Robots - Safety. France: ISO Publications, 1992.

INOVAÇÃO TECNOLÓGICA. Robôs agrícolas farão colheita de frutas de forma autônoma. 30/08/2007. Online. Disponível em: <www.inovacaotecnologica.com.br/ noticias $/$ noticia.php? artigo $=010180070830>$. Acesso em: set. 2012.

JORGE, Lúcio André de Castro; TRINDADE JUNIOR, Onofre. Metodologia para utilização de aeromodelos em monitoramento aéreo. Circular Técnica, Embrapa Instrumentação Agropecuária, São Carlos, SP, n. 15, 2002. Disponível em: <http://www.infoteca.cnptia. embrapa.br/bitstream/doc/28442/1/CiT152002.pdf> Acesso em: out. 2012.

KITAMURA, S.; OKA, K. Recognition and cutting system of sweet pepper for picking robot in greenhouse horticulture. In: IEEE INTERNATIONAL CONFERENCE ON MECHATRONICS AND AUTOMATION, 29 july-1 aug. 2005, Niagara Falls, Canada. Anais... IEEE, 2005, p. 1807-1812. (v. 4).

LAMM, R.; SLAUGHTER, D.; GILES, D. Precision Weed Control System for Cotton.Transactions of the ASABE, 45(1), p. 231-238, 2002.

LIBIN, Z. et al. Overview of research on agricultural robots in China. Int J Agric Biol Eamp; Eng., 2008. Disponível em: <www.ijabe.org/index.php/ijabe/article/ download/14/21>. Acesso em: out. 2012.

LOWENBERG-DeBOER, J.; GRIFFIN, T. W. Potential For Precision Agriculture Adoption In Brazil. Site - Specific Management Center, West Lafayette, Purdue University, 2006. Disponível em: <http:/ / www.agriculture.purdue.edu/SSMC/Frames/SSMC_newsletter6_06.pdf>.

MANDOW, A. et al. The autonomous mobile robot Aurora for greenhouse operation. IEEE Robot. Auto. Mag., 3:18-28, 1996. 
NOGUCHI, N. Development of Automated and Robot Agriculture in Japan. Journal of Agricultural Engineering Research, Sapporo, Hokkaido University. 2010. Disponível em: <http://www.nt.ntnu.no/users/skoge/ prost/proceedings/ifac11-proceedings/data/html/ papers/38 38.pdf>. Acesso em: out. 2012.

OLIVEIRA, R. P. Agricultura de precisão: a Tecnologia da Informação em suporte ao conhecimento agronômico clássico. Revista Tecnologia \& Cultura, Rio de Janeiro, ano 11, n. 15, p. 63-71, jul./dez. 2009.

RUCKELSHAUSEN, A. Ansätze und Trends zur Roboterisierung in der Landwirtschaft. In: SYMPOSIUM ROBOT TO BUSINESS - MOBILE ANWENDUNGEN ZUR OPTIMIERUNG VON GESCHÄFTSPROZESSEN, 11 juni 2010, Braunschweig: Fachhochschule Osnabrück, Johann Heinrich von Thünen-Institut, 2010.

SANCHEZ, H. J. et al. Mechanical Design and Development of an Electric Mobile Robot for Agricultural Tasks in Greenhouses. Almería: University of Almería, Agrifood Campus of International Excellence, 2011.

SANDINI, G. et al. Visually Guid ed Operations in Greenhouses. In: IEEE INTERNATIONAL WORKSHOP ON INTELLIGENT ROBOTS AND SYSTEMS, july 1990, Ibaraki, Japan. Anais... IEEE, 1990, p. 279-285.

SILVEIRA, P. C. R. Robô baseado em tecnologia celular Android e lógica nebulosa para inspeção e monitoração em usinas nucleares. 2012. Dissertação (Mestrado em Engenharia Nuclear) - COPPE/Programa de Engenharia Nuclear, Universidade Federal do Rio de Janeiro, Rio de Janeiro, 2012.

SINGH, S.; LEE, W. S.; BURKS, T. F. Autonomous Robotic Vehicle Development for Greenhouse Spraying. Transactions of the ASAE, St. Joseph, v. 48, n. 6, 2005.

SUBRAMANIAN, V.; BURKS, T. F. SINGH, $S$.Autonomous greenhouse sprayer vehicle using machine visión and ladar for steering control. Appl. Eng. Agric., v. 21, p. 935-943, 2005.

TANGERINO, G. et al. Controle de esterçamento de robô agrícola móvel de quatro rodas guiáveis. In: SIMPOSIO BRASILEIRO DE AUTOMAÇÃO INTELIGENTE - SBAI, 10., 18-21 set. 2011. São João del-Rei, MG, Brasil. Anais... São João del-Rei, 2011. (v. X).

TANKE, N. F. et al. Automation of Hydroponic Installations using a Robot with Position Based Visual Feedback. Pittsburgh: The Robotics Institute, Carnegie Mellon University, 2011.

VAN HENTEN, E. J. et al. An autonomous robot for harvesting cucumbers in greenhouses. Autonom. Robot., Los Angeles, v. 13, n. 3, p. 241-258, 2002.

YAMAGATA, N. The integrated agricultural GIS: GeoMation Farm, Proceedings of 4th Asian Conference on Precision Agriculture, O-32, 2011. 